\title{
Application and Exploration of Carbon Dioxide R744 as Refrigerant and Secondary Refrigerant in Refrigerating Unit of Commercial Super
}

\author{
Li Guangpeng ${ }^{1,2^{*}}$, Wang Qi ${ }^{1}$ and Shao Changbo ${ }^{1}$ \\ ${ }^{1}$ School of Intelligent Manufacturing and Service, Shandong Institute of Commerce and Technology, Jinan, China \\ ${ }^{2}$ School of Mines, China University of Mining and Technology, Xuzhou, China
}

\begin{abstract}
In this paper, the cascade refrigeration system and the load cooling system of the natural working medium are integrated as one unit system, which can meet the needs of different temperature zones of refrigerating in supermarkets. The concrete implementation scheme of the unit system with R717 as high temperature refrigerant, $\mathrm{CO} 2$ as low temperature refrigerant and carrier refrigerant was designed. According to the actual load of commercial super, the design and calculation of $\mathrm{NH} 3$ refrigerant system, $\mathrm{CO} 2$ refrigerant carrier system and $\mathrm{CO} 2$ cryogenic system were carried out. Through calculation and testing, the ideal refrigeration effect of the unit is obtained. Compared with the traditional unit, the energy saving is $20 \%$, emission reduction (translated into $\mathrm{CO} 2$ emission) is $40 \%$, and the operation cost is reduced by $20 \%$.
\end{abstract}

\section{Introduction}

The general cold temperature zone from $-30^{\circ} \mathrm{C}$ to $-40^{\circ} \mathrm{C}$ is widely used in commercial refrigeration fields, such as low-temperature display cabinets and freezers in supermarkets[1]. At present, CFCs and HCFCs refrigerants, which are harmful to the environment, are still used in refrigeration systems of large supermarkets in China[2,3]. These substances not only destroy the ozone layer of the atmosphere, but also cause serious greenhouse effect. CFCs are currently restricted under "Montreal Protocol", and HCFCs have until 2030[4]. In this paper, $\mathrm{R} 717 / \mathrm{CO} 2$ cascade refrigeration unit is designed for commercial refrigeration in supermarkets. $\mathrm{CO} 2$ is not only a refrigerant for display cabinets in high-temperature supermarkets, but also a refrigerant for cold storage in low temperature. The refrigerants of the refrigeration system are all environmentally friendly working substances, and the ozone depletion potential value is 0.At the same time, the food is free from pollution, to ensure the quality of goods. The system runs safely and reliably.

\section{Design Scheme}

The refrigerant in this scheme is a superimposed system of environmental protection refrigerant R717 and CO2. The CO2 system has two temperature gradient evaporators, which are cryogenic storage and preservation display cabinet. The cold storage adopts the direct expansion technology of electronic expansion valve for liquid supply, and the display cabinet adopts the refrigeration technology of pump forced circulation of refrigerant carrier. R717 serves as the condenser for the $\mathrm{CO} 2$ system on the high temperature side.

\subsection{Technical principle of refrigerating unit}

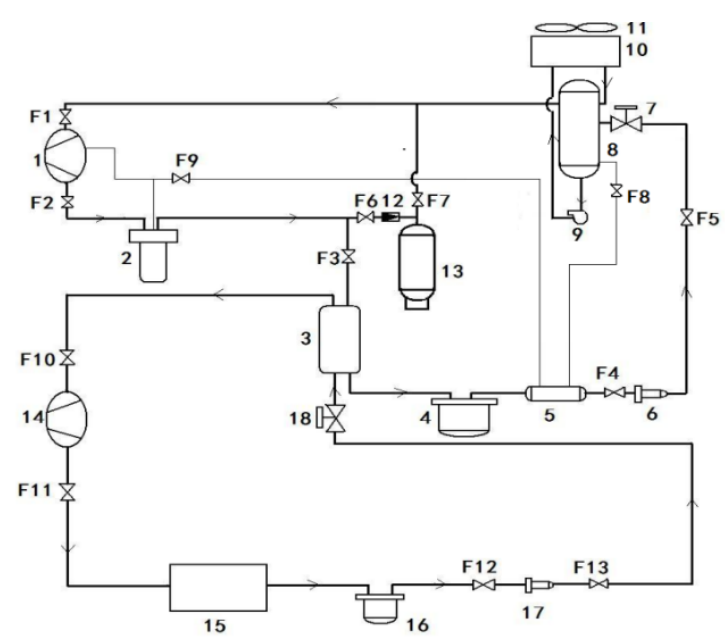

1- Low temperature compressor. 2- Oil separator. 3Evaporative condenser. 4, 16- Reservoir. 5- Economizer. 6, 17-

Throttle valve. 7, 18- magnetic valve. 8- Low pressure circulating drum. 9- Ammonia pump. 10,11- Evaporator. 12Check valve. 13- Set of tank. 14-High temperature compressor. 15- Condenser. F1 to F13- Globe valve.

Figure 1. Working principle of R717/CO2 cascade refrigeration unit

The NH3(R717)/CO2(R744) drum pump is composed of the R717 air-cooled condensing unit of the high temperature stage and the $\mathrm{CO} 2$ drum pump and evaporative condenser of the low temperature system. The cryogenic compressor inhales the vaporized $\mathrm{CO} 2$ from the 
low-pressure circulation barrel. The compressor exhaust is fed into the $\mathrm{R} 717 / \mathrm{CO} 2$ evaporative condenser, where it is evaporated and condensed into $\mathrm{CO} 2$ liquid by high temperature $\mathrm{R} 717$. After the condensed $\mathrm{CO} 2$ liquid is heat exchanged by the return oil heat exchanger, it is throttled through the throttle expansion valve and then enters the $\mathrm{CO} 2$ circulation nozzle into low temperature and low pressure liquid. The low temperature and low pressure $\mathrm{CO} 2$ liquid is sent to the single freezer by $\mathrm{CO} 2$ pump for evaporation and heat absorption. The R717 high temperature compressor inhales the evaporated gas in the evaporative condenser, and the exhaust gas enters the aircooled condenser and condenses into liquid, which is then throttled to the evaporative condenser to complete the circulation. The R717 high temperature system and the $\mathrm{CO} 2$ barrel pump are designed in the same way as ordinary single-stage units.

\subsection{The concrete implementing scheme}

$\mathrm{CO} 2$ is used as the low-temperature working medium of the cladding system.CO2 liquid at low temperature has small viscosity, small flow resistance, small pipe size, low pump energy consumption, good thermal conductivity, high heat exchange efficiency, no corrosion to refrigeration equipment, no pollution to food, is a natural working medium, environmentally friendly. But the working pressure of the system is higher.

$\mathrm{NH} 3$ is used as the high temperature working medium of the cladding system. It has good thermodynamic properties, is also a natural working medium, environmentally friendly. Its disadvantages are moderately toxic, flammable and insoluble with ordinary mineral based lubricants.

The closed cooling tower is used for high-temperature ammonia circulation, and special plate heat exchanger is used for $\mathrm{NH} 3 / \mathrm{H} 2 \mathrm{O}$ heat exchange. $\mathrm{NH} 3 / \mathrm{CO} 2$ intermediate evaporative condenser adopts $\mathrm{NH} 3 / \mathrm{CO} 2$ special plate replacement. And an economic device is provided.

The low temperature carbon dioxide circulation is divided into two channels for liquid supply. The low temperature system uses $\mathrm{CO} 2$ special compressor for circulation refrigeration, while the medium temperature system uses $\mathrm{CO} 2$ special pump for forced circulation refrigeration, without compressor.

\section{System design and calculation}

\subsection{Design and calculation of NH3 refrigerant system}

\subsubsection{The original parameters}

Unit load: $33 \mathrm{KW}$;

- Refrigeration medium: R717;

- Climatic conditions: Outdoor ambient temperature (summer ventilation temperature) $29^{\circ} \mathrm{C}$, wet bulb temperature $20^{\circ} \mathrm{C}$

- Evaporation temperature: - $10{ }^{\circ} \mathrm{C}$, degree of superheat $\Delta=3 \sim 8{ }^{\circ} \mathrm{C}$;

- The condensation temperature is $30^{\circ} \mathrm{C}$, and the undercooling degree is $5^{\circ} \mathrm{C}$.

\subsubsection{R717 refrigeration system circulation schematic diagram}

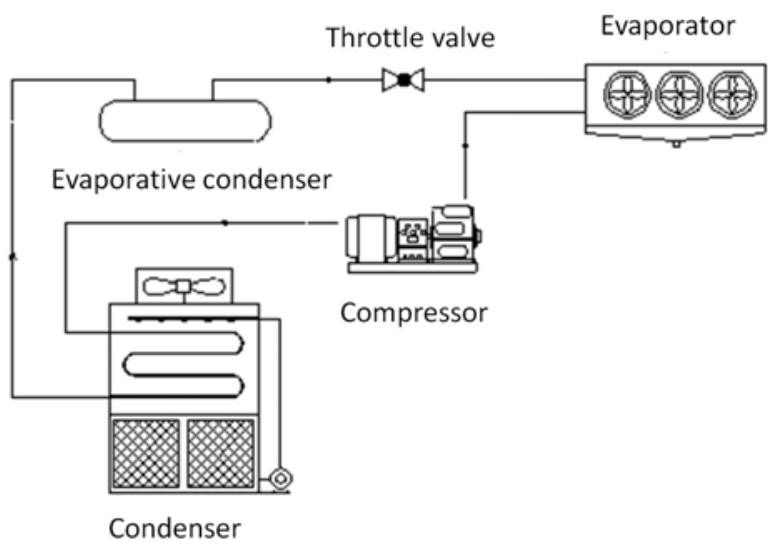

Figure 2. R717 refrigeration system circulation principle

\subsubsection{Mathematical model}

The parameters (such as temperature, density and specific volume) of the refrigerant in the inlet pipe, compressor and exhaust pipe in the actual refrigeration cycle are threedimensional non-uniform distribution parameters. It would cause a lot of trouble if we calculated it in real terms. It can be assumed that the temperature, density and specific volume of the gas are uniformly distributed in the inlet and exhaust pipes, that is, it is assumed that the thermodynamic parameters of the working medium are uniformly distributed. After the compression process is calculated as isentropic process, it is corrected by the compressor's electrical efficiency.

The following mathematical model was established by using empirical formula: $\mathrm{R} 717$ evaporation temperature is $-10^{\circ} \mathrm{C}$, superheat is $3-8{ }^{\circ} \mathrm{C}$ (take $5^{\circ} \mathrm{C}$ ), condensation temperature is $30{ }^{\circ} \mathrm{C}$, undercooling degree is $5^{\circ} \mathrm{C}$, the ambient wet-bulb temperature is $20^{\circ} \mathrm{C}$.

\subsubsection{Thermodynamic parameter calculation}

Looking up Figure 3, the physical parameters are as follows:

- $t_{1}=-10^{\circ} \mathrm{C}, p_{1}=0.29 \mathrm{MPa}, h_{1}=1450 \mathrm{~kJ} / \mathrm{kg}$

- $t_{1}{ }^{\prime}=-5^{\circ} \mathrm{C}, \quad v_{1}{ }^{\prime}=0.43 \mathrm{~m}^{3} / \mathrm{kg}, h_{1}{ }^{\prime}=1468 \mathrm{~kJ} / \mathrm{kg}$

- $t_{2}=30^{\circ} \mathrm{C}, h_{2}=1652 \mathrm{~kJ} / \mathrm{kg}$

- $h_{2 s}=h_{1}+\frac{h_{2}-h_{1}}{\eta_{t 2}}=1698 \mathrm{~kJ} / \mathrm{kg}, p_{2 s}=1.25 \mathrm{MPa}, t_{2 s}=95^{\circ} \mathrm{C}$

- $t_{3}{ }^{\prime}=30^{\circ} \mathrm{C}, h_{3}{ }^{\prime}=349 \mathrm{~kJ} / \mathrm{kg}$

- $t_{3}=25^{\circ} \mathrm{C}, h_{3}=245 \mathrm{~kJ} / \mathrm{kg}$

- $t_{4}=-10^{\circ} \mathrm{C}, h_{4}=245 \mathrm{~kJ} / \mathrm{kg}$ 
$\operatorname{lgp}$

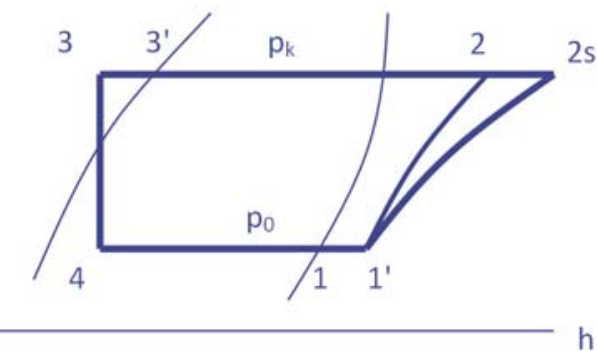

Figure 3. P-H diagram of refrigeration cycle

Cooling capacity per unit mass,

$q_{0}=h_{1}-h_{4}=1205 \mathrm{~kJ} / \mathrm{kg}$

Theoretical power consumption per unit mass,

$w_{0}=h_{2}-h_{1}{ }^{\prime}=184 \mathrm{~kJ} / \mathrm{kg}$

Mass flow rate of refrigerant,

$q_{m}=Q_{0} / q_{0}=0.027 \mathrm{~kg} / \mathrm{s}$

Theoretical transport volume,

$V_{s}=q_{m} v_{1}{ }^{\prime}=0.012 \mathrm{~m}^{3} / \mathrm{s}$

Actual gas capacity,

$$
V_{h}=V_{h} / \lambda=0.016 \mathrm{~m}^{3} / \mathrm{s}
$$

The theoretical power of compressor,

$$
P_{0}=q_{m} w_{0}=4.978 \mathrm{~kW}
$$

Indicated power of the compressor,

$$
P_{i}=P_{0} / \eta_{i}=6.21 \mathrm{~kW}, \eta_{i}=0.8
$$

The shaft power of the compressor,

$$
P_{e}=P_{i} / \eta_{e}=7.306 \mathrm{~kW}, \eta_{e}=0.85
$$

The cooling load,

$$
Q_{c}=Q_{0} \times\left(h_{2 s}-h_{3}\right) /\left(h_{1}-h_{4}\right)=37.03 \mathrm{~kW}
$$

\subsection{Design and calculation of $\mathrm{CO} 2$ coolant carrier system}

\subsubsection{Circulating schematic diagram of $\mathrm{CO} 2$ coolant carrier system}

The $\mathrm{CO} 2$ carrying cold circulation system includes refrigeration circulation system, $\mathrm{CO} 2$ reservoir, liquid $\mathrm{CO} 2$ circulation pump, air cooler, safety valve, etc. [5]

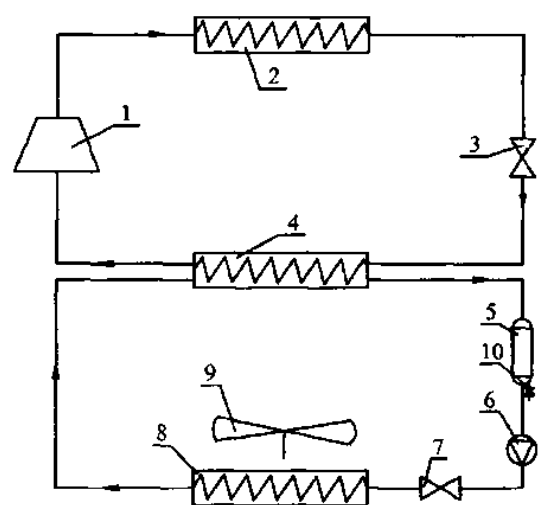

1-Compressor. 2- Condenser. 3-Expansion valve. 4Evaporative condenser. 5-Liquid reservoir. 6- CO2 liquid pump. 7-flow control valve. 8-Air cooler. 9- Fan. 10- Emergency relief valve

Figure 4. Diagram of $\mathrm{CO} 2$ carrying cooling circulation system

\subsubsection{Determination of mass flow rate of $\mathrm{CO} 2$}

The mass flow rate of $\mathrm{CO} 2$ carrying cold cycle is

$$
m=Q / r=7000 / 313.41=22.3 \mathrm{~g} / \mathrm{s}
$$

\subsubsection{Determination of pipe diameter and wall thickness of refrigerant carrying pipe}

The critical temperature of $\mathrm{CO} 2$ is $31.1{ }^{\circ} \mathrm{C}$, the triple point pressure is $518 \mathrm{kPa}$, and the triple point temperature is $56.56{ }^{\circ} \mathrm{C}$. At $101.325 \mathrm{kPa}$, the sublimation temperature is $-78.15^{\circ} \mathrm{C}$. At $0^{\circ} \mathrm{C}$, the pressure of $\mathrm{CO}$-saturated liquid is 3.48MPa. Therefore, to transfer the cooling capacity from $-50^{\circ} \mathrm{C}$ to $0^{\circ} \mathrm{C}$, the pressure of the cooling pipe must be guaranteed within the range $0.52 \sim 3.48 \mathrm{MPa}$, and the ordinary copper pipe can meet the pressure requirements.

\subsection{Design and calculation of $\mathrm{CO} 2$ cryogenic system}

\subsubsection{Working condition}

The load of the unit is $25 \mathrm{KW}$. NH3 and $\mathrm{CO} 2$ are used as refrigerants in the system. $\mathrm{CO} 2$ is used as refrigerant in low temperature stage and $\mathrm{NH} 3$ is used as refrigerant in high temperature stage. The calculated dry bulb temperature of outdoor ventilation in summer is $31^{\circ} \mathrm{C}$.

\subsubsection{Thermodynamic calculation}

Cooling capacity per unit mass,

$$
q_{0}=h_{1}-h_{4}=736.06-465.2=270.86 \mathrm{~kJ} / \mathrm{kg}
$$

Theoretical power consumption per unit mass,

$$
w_{0}=h_{2}-h_{1}{ }^{\prime}=788.9-741.66=47.24 \mathrm{~kJ} / \mathrm{kg}
$$

Mass flow rate of refrigerant, 


$$
q_{m}=Q_{0} / q_{0}=0.0923 \mathrm{~kg} / \mathrm{s}
$$

Theoretical transport volume,

$$
V_{s}=q_{m} v_{1}{ }^{\prime}=0.0042 \mathrm{~m}^{3} / \mathrm{s}
$$

Actual gas capacity,

$$
V_{h}=V_{h} / \lambda=0.00525 \mathrm{~m}^{3} / \mathrm{s}
$$

The theoretical power of compressor,

$$
P_{0}=q_{m} w_{0}=4.36 \mathrm{~kW}
$$

Indicated power of the compressor,

$$
P_{i}=P_{0} / \eta_{i}=6.23 \mathrm{~kW}, \eta_{i}=0.7
$$

The shaft power of the compressor,

$$
P_{e}=P_{i} / \eta_{e}=7.79 \mathrm{~kW}, \eta_{e}=0.80
$$

\section{Specific implementation effect}

The project has been applied in engineering, and the ideal refrigeration effect of unit has been obtained through calculation and testing. The refrigeration unit of low temperature cold storage and high temperature display cabinet adopts $\mathrm{R} 717 / \mathrm{CO} 2$ duplicated refrigeration, and the unit system uses R717 as high temperature refrigerant and $\mathrm{CO} 2$ as low temperature refrigerant and refrigerant carrier. For the R717 side, the condensation temperature is $35^{\circ} \mathrm{C}$ and the evaporation temperature is $-15^{\circ} \mathrm{C}$. For the $\mathrm{CO} 2$ side, the condensing temperature is $-10^{\circ} \mathrm{C}$, the evaporation temperature of the low temperature cold storage is $-28^{\circ} \mathrm{C}$, and the evaporation temperature of the high temperature display cabinet is $-10{ }^{\circ} \mathrm{C} \quad(\mathrm{CO} 2$ is used as the load refrigerant). After testing, the COP of the system is 1.5 . Compared with traditional units, it saves energy by $20 \%$, reduces emissions (translated into $\mathrm{CO} 2$ emissions) by $40 \%$ and reduces operating costs by $20 \%$.

\section{Acknowledgments}

Thanks to the Smart Cold Chain Integration Technology Research Center for providing a platform for the implementation of this project. Thanks very much to the members of the teaching team of refrigeration major for their support to this work.

\section{References}

1. Wang Qi , Li Guangpeng. (2O20) Research and Development of Carbon Dioxide Refrigeration Technology. E3S Web of Conferences, 213:03031.

2. Tian Yafen, Zhao Zhaorui, Xing Ziwen, Yang Yifan, Ma Jin, Yu Zhiqiang.(2016) Study on Application Scope for CO2 Cascade Refrigeration System and $\mathrm{CO} 2$ Secondary Refrigerant System[J]. Journal of Refrigeration, 37(O2),22-29.
3. Yefeng Liu,Ying Sun,Dongliang Wang. (2019)Research on carbon dioxide transcritical refrigeration cycle with vortex tube[J]. IOP Conference Series: Earth and Environmental Science, 267(2),67-71.

4. Mikolaj Mastrowski,Jacek Smolka,Armin Hafner,Michal Haida,Michal Palacz,Krzysztof Banasiak.(2019) Experimental study of the heat transfer problem in expansion devices in $\mathrm{CO} 2$ refrigeration systems. Energy, 173:23-27.

5. Hafner A, Frsterling S, Banasiak K.(2014) Multiejector concept for R -744 supermarket refrigeration. International Journal of $R$ efrigeration,43(4) : 1-13. 